\title{
GAMBARAN FUNGSI SEKSUAL WANITA MENOPAUSE
}

\author{
Yhenti Widjayanti \\ STIKES Katolik St. Vincentius A Paulo Surabaya, Jln. Jambi No 12-18 Surabaya
}

\begin{abstract}
ABSTRAK
Menopause merupakan kondisi normal yang dialami wanita seiring dengan pertambahan usia. Saat menopause, produksi hormon estrogen dan progesteron mulai berkurang dan menimbulkan gejala fisik dan psikis yang berakibat timbulnya disfungsi seksual. Tujuan penelitian ini adalah mendapatkan gambaran tentang fungsi seksual wanita menopause. Desain penelitian ini adalah deskriptif. Responden penelitian ini adalah 35 wanita menopause di RT 12 dan 13 RW V Kelurahan Darmo Kecamatan Wonokromo Surabaya yang memenuhi kriteria inklusi dan dikumpulkan menggunakan teknik simple random sampling. Variabel penelitian ini adalah fungsi seksual wanita menopause diukur dengan FSFI (Female Sexual Function Index). Hasil penelitian didapatkan lebih dari $50 \%(51 \%)$ responden memiliki fungsi seksual baik dan $49 \%$ memiliki fungsi seksual buruk. Kader kesehatan diharapkan dapat bekerjasama dengan Puskesmas dalam memberikan penyuluhan tentang upaya untuk mengatasi gejala menopause khususnya yang terkait dengan fungsi seksual bagi wanita menopause agar wanita menopause dapat memiliki fungsi seksual yang baik
\end{abstract}

Kata Kunci: Fungsi seksual, Menopause

\begin{abstract}
Menopause is a normal condition that will be experienced by women along with their age. During menopause, the production of estrogen and progesterone hormone begins to decrease and cause sexual disfunction. The purpose of this study was to describe menopausal women's sexual function. The design of this research was a descriptive study. Respondents were 35 menopausal women at $R T 12$ and 13 RW V, Kelurahan Darmo, Wonokromo District Surabaya who fulfilled the inclusion criteria. They were selected by using simple random sampling technique. The variables in this study were female sexual function measured by the FSFI (Female Sexual Function Index) questionnaires. The result showed that more than 50\% (51\%) respondents has good sexual function. Suggestions for RT was together with Puskesmas Jagir in giving counseling about how to decrease the menopausal symptoms especially about sexual function.
\end{abstract}

Keywords: Sexual Function, Menopause 


\section{PENDAHULUAN}

Menopause merupakan kondisi normal yang akan dialami oleh semua wanita seiring dengan pertambahan usia (Haryono, 2016). Pada masa menopause, indung telur mulai menghentikan produksi estrogen dan progesteron sehingga hormon estrogen dan progesteron dalam tubuh mulai berkurang (Smart, 2010). Turunnya kadar estrogen pada wanita menopause akan menyebabkan terganggunya fungsi seksual. Minat untuk melakukan hubungan intim menurun drastis karena tidak lagi merasakan rangsangan seksual yang diberikan oleh pasangan. Penurunan kadar estrogen juga menyebabkan terjadinya penurunan suplai darah ke vagina sehingga produksi lendir vagina menjadi menurun. Keadaan ini membuat vagina menjadi kering dan timbul rasa sakit saat berhubungan intim (Wirawan, 2013, hal: 32).

Berdasarkan data WHO (2010) jumlah wanita menopause di Asia pada tahun 2025 akan mencapai 373 juta jiwa. Di Indonesia tahun 2020 wanita menopause dengan usia rata-rata 49 tahun sebanyak 30,3 juta (Susanti, 2014). Berdasarkan survei awal yang dilakukan peneliti di RT 12 RW V Kelurahan Darmo Kecamatan Wonokromo Surabaya menunjukkan dari 10 orang wanita menopause didapatkan 5 orang mengatakan sudah tidak memiliki kekuatan yang sama seperti waktu masih muda, 3 orang merasa diri tua, 4 orang merasa takut dengan perubahan yang terjadi seperti kulit yang menjadi kendur dan keriput yang membuat penampilan tidak menarik lagi dan hal tersebut tentu saja berpengaruh pada kehidupan seksual mereka.

Jika fungsi seksual tidak dapat berfungsi dengan baik maka akan mempengaruhi kualitas hidup dan hubungan dengan pasangan (Melliana, 2006). Pola hidup sehat seperti olahraga teratur, serta mengonsumsi makanan sehat yang mengandung fitoestrogen alami yang terkandung dalam makanan seperti kedelai, tempe, tahu dan buah-buahan disarankan untuk meringankan gejala menopause termasuk yang berkaitan dengan kebutuhan seksual (Smart, 2010).

Tujuan penelitian ini adalah mendapatkan gambaran tentang fungsi seksual wanita menopause di RT 12 dan 13 RW V Kelurahan Darmo Kecamatan Wonokromo Surabaya.

\section{BAHAN DAN METODE}

Desain penelitian ini adalah studi deskriptif. Pengambilan data dilakukan di RT 12 dan 13 RW V Kelurahan Darmo Kecamatan Wonokromo Surabaya pada tanggal 9 dan 12 April 2017. Responden dalam penelitian ini adalah 35 wanita menopause yang memenuhi kriteria inklusi bersedia menjadi responden, aktif dalam kegiatan PKK, bisa membaca dan menulis, serta menikah dan masih memiliki pasangan. Teknik pengambilan sampel menggunakan simple random sampling.

Instrumen yang digunakan adalah FSFI (Female Sexual Function Index). Instrumen ini digunakan untuk mengukur fungsi seksual wanita. Kuesioner ini mengandung 19 
pertanyaan meliputi 2 soal gairah seksual, 4 soal bangkitan seksual, 4 soal pelendiran vagina, 3 soal orgasme, 3 soal kepuasan, dan 3 soal rasa sakit. FSFI (Female Sexual Function Index) sudah teruji validitas dan reliabilitas secara internasional.

Data yang didapatkan dianalisis secara analisa statistik deskriptif proporsi prosentase.

\section{HASIL}

Tabel 1 Karakteristik Responden

\begin{tabular}{|c|c|c|c|}
\hline $\begin{array}{c}\text { Karakteristik } \\
\text { Responden }\end{array}$ & $\begin{array}{c}\text { Frekue } \\
\text { nsi (n) }\end{array}$ & $\begin{array}{l}\text { Prosent } \\
\text { ase }(\%)\end{array}$ & \\
\hline & Mean \\
\hline $45-59$ & 35 & $100 \%$ & $\pm \mathrm{SD}$ \\
\hline & 51,34 \\
\hline Normal & 12 & $34 \%$ & \pm \\
\hline Gemuk & 5 & $14 \%$ & 4,345 \\
\hline Obesitas & 18 & $52 \%$ & Min : \\
\hline \multicolumn{3}{|l|}{ Status } & 45 \\
\hline Pekerjaan & 15 & $43 \%$ & Max: \\
\hline Bekerja & 20 & $57 \%$ & 59 \\
\hline \multicolumn{4}{|l|}{ Tidak Bekerja } \\
\hline Agama & 30 & $86 \%$ & \\
\hline Islam & 1 & $3 \%$ & \\
\hline Kristen & 4 & $11 \%$ & \\
\hline \multicolumn{4}{|l|}{ Katolik } \\
\hline \multicolumn{4}{|l|}{ Keaktifan } \\
\hline \multicolumn{4}{|l|}{ dalam } \\
\hline \multicolumn{4}{|l|}{ kegiatan } \\
\hline \multicolumn{4}{|l|}{ keagamaan } \\
\hline Ya & 23 & $66 \%$ & \\
\hline Tidak & 12 & $34 \%$ & \\
\hline \multicolumn{4}{|l|}{ Keaktifan } \\
\hline \multicolumn{4}{|l|}{ dalam } \\
\hline \multicolumn{4}{|l|}{ kegiatan sosial } \\
\hline Ya & 35 & $100 \%$ & \\
\hline Tidak & 0 & 0 & \\
\hline \multicolumn{4}{|l|}{ Lama } \\
\hline \multicolumn{4}{|l|}{ Menopause } \\
\hline 1 tahun & 18 & $52 \%$ & \\
\hline 2-3 tahun & 7 & $20 \%$ & \\
\hline 4-5 tahun & 6 & $17 \%$ & \\
\hline$>5$ tahun & 4 & $11 \%$ & \\
\hline \multicolumn{4}{|l|}{$\begin{array}{l}\text { Olah raga } \\
\text { rutin }\end{array}$} \\
\hline Ya & 3 & $9 \%$ & \\
\hline Tidak & 32 & $91 \%$ & \\
\hline \multicolumn{4}{|l|}{ Penggunaan } \\
\hline
\end{tabular}

\begin{tabular}{|c|c|c|}
\hline $\begin{array}{c}\text { Karakteristik } \\
\text { Responden }\end{array}$ & $\begin{array}{l}\text { Frekue } \\
\text { nsi (n) }\end{array}$ & $\begin{array}{l}\text { Prosent } \\
\text { ase }(\%)\end{array}$ \\
\hline \multicolumn{3}{|l|}{ Hormon } \\
\hline Ya & 0 & 0 \\
\hline \multicolumn{3}{|l|}{ Penyakit } \\
\hline Hipertensi & 10 & $26,3 \%$ \\
\hline Diabetes & 2 & $5,26 \%$ \\
\hline $\begin{array}{l}\text { Penyakit tulang } \\
\text { dan persendian }\end{array}$ & 28 & $73,7 \%$ \\
\hline $\begin{array}{l}\text { Merokok } \\
\text { Ya }\end{array}$ & 0 & 0 \\
\hline Tidak & 35 & $100 \%$ \\
\hline \multicolumn{3}{|l|}{ Konsumsi } \\
\hline \multicolumn{3}{|l|}{ Alkohol } \\
\hline Ya & 0 & 0 \\
\hline Tidak & 35 & $100 \%$ \\
\hline \multicolumn{3}{|c|}{ Tabel 2 Fungsi Seksual } \\
\hline Fungsi & Frekuensi & Prosentase \\
\hline Seksual & (n) & $(\%)$ \\
\hline Baik & 18 & $51 \%$ \\
\hline Buruk & 17 & $49 \%$ \\
\hline
\end{tabular}

Hasil penelitian menunjukkan bahwa lebih dari $50 \%$ wanita menopause memiliki fungsi seksual yang baik.

\section{PEMBAHASAN}

Hasil penelitian didapatkan 18 responden $(51 \%)$ responden memiliki fungsi seksual baik dan 17 (49\%) responden memiliki fungsi seksual buruk. Menurut Pangkahila (2014) pada masa menopause indung telur mulai menghentikan produksi estrogen dan progesteron sehingga hormon estrogen dan progesteron dalam tubuh mulai berkurang. Penurunan hormon tersebut akan menimbulkan gejala baik fisik seperti hot flushes, insomnia, kekeringan pada vagina, maupun gejala psikis seperti kecemasan dan 
stres dapat mengganggu fungsi seksual wanita. Kekeringan vagina akan berakibat seorang wanita merasakan ketidaknyamanan saat berhubungan seksual. Hal ini berpengaruh pada fungsi seksual wanita tersebut. Disfungsi seksual adalah masalah yang mengakibatkan individu atau pasangannya tidak dapat menikmati hubungan seksual dan orgasme. Disfungsi seksual mungkin terjadi sebagai akibat dari gangguan fisiologis, konflik budaya, masalah interpersonal, atau kombinasi dari ketiganya (Williams \& Wilkins, 2011)

Beberapa faktor yang dapat mempengaruhi berat ringannya gejala menopause termasuk gangguan fungsi seksual yang dirasakan oleh wanita menopause antara lain gaya hidup seperti kebiasaan olahraga, konsumsi alkohol dan rokok, kelebihan berat badan atau obesitas, penyakit, lama menopause dan penggunaaan terapi hormon.

Bila dilihat dari faktor kebiasaan olahraga didapatkan dari 14 (93\%) responden yang tidak memiliki kebiasaan olahraga. Menurut Sugani (2010) kadar hormon estrogen dalam tubuh berhubungan dengan neurotransmiter diantaranya adalah endorfin yang merupakan sistem kimia otak yang berfungsi mempengaruhi persepsi rasa nyeri, suhu tubuh, tekanan darah, ingatan serta tingkah laku seksual. Endorfin sangat responsif terhadap fluktuasi kadar estrogen dan progesteron. Pada masa menopause kadar endorfin menjadi turun. Namun, olahraga dapat meningkatkan produksi endorphine dalam otak. Kondisi ini membuat selalu gembira, pengiriman oksigen ke otak akan meningkat sehingga ketegangan otot dan berbagai gangguan fisik dapat diatasi. Sesuai dengan teori saat responden tidak berolahraga maka akan berpengaruh pada kadar endorfin dalam otak, dimana endorfin mempengaruhi persepsi rasa nyeri, suhu tubuh, tekanan darah, ingatan, tingkah laku seksual dan pengaturan mood. Saat tubuh kekurangan endorfin maka kemampuan tubuh untuk mengontrol rasa nyeri, suhu, tekanan darah, ingatan, tingkah laku seksual dan pengaturan mood akan terganggu. Masalah tersebut semakin diperparah oleh adanya ketidakseimbangan hormon pada wanita menopause.

Bila dilihat dari lama menopause didapatkan dari 17 responden yang mengalami gangguan fungsi seksual sebanyak $9(60 \%)$ responden mengalami menopause selama 1 tahun. Menurut Smart (2010) pada saat menopause terjadi perubahan fungsi indung telur sehingga indung telur lebih sedikit menghasilkan atau memproduksi hormon estrogen dan progesteron. Semakin lama menopause maka produksi estrogen dan progesteron oleh indung telur semakin berkurang sampai akhirnya tidak diproduksi lagi. Dari hasil penelitian didapatkan responden yang baru menopause selama 1 tahun justru mengalami disfungsi seksual. Hal ini dikarenakan responden belum terbiasa dengan perubahan dan gejala menopause yang terjadi sehingga belum beradaptasi dengan perubahan fisik yang dirasakan. Responden yang mengalami menopause lebih lama secara perlahan sudah dapat menyesuaikan diri dengan perubahan yang terjadi sehingga 
gejala yang dirasakan tidak seberat saat pertama kali menopause.

Bila dilihat dari indeks masa tubuh didapatkan dari 17 responden yang mengalami gangguan fungsi seksual sebanyak $10(67 \%)$ responden yang masuk dalam kategori obesitas. Menurut Lingga (2011) timbunan lemak pada perempuan obesitas juga mempengaruhi sistem reproduksi, perubahan hormonal dan ketidakseimbangan hormon. Pertambahan usia serta gangguan keseimbangan hormon pada wanita menopause membuat masalah radang dan nyeri sendi pada orang gemuk semakin mengkhawatirkan. Sesuai dengan teori responden yang memiliki kelebihan berat badan akan mempengaruhi keseimbangan hormon reproduksi yang menyebabkan responden mengalami berbagai gejala seperti mood yang berubah-ubah dan juga kekeringan pada vagina.

18 responden memiliki fungsi seksual baik. Seluruh responden tersebut aktif dalam kegiatan keagamaan. Menurut Sunaryo (2015) ibadah merupakan cara untuk memenuhi kebutuhan spiritual. Kebutuhan spiritual erat kaitannya dengan kebutuhan seksual. Hasil wawancara menyebutkan bahwa sesuai kepercayaan yang dianut oleh wanita tersebut melayani pasangan secara seksual merupakan suatu kewajiban. Sehingga responden dan dan pasangan mencoba untuk melakukan hubungan seksual yang nyaman dan dapat dinikmati oleh kedua belah pihak.

\section{SIMPULAN}

Hasil penelitian menunjukkan bahwa ada hubungan antara gejala menopause dengan kualitas hidup pada wanita menopause, dimana peningkatan gejala menopause diikuti dengan penurunan kualitas hidup.

\section{SARAN}

Peneliti menyarankan kepada pihak RT untuk bekerjasama dengan Puskesmas dalam memberikan penyuluhan tentang upaya untuk mengatasi gejala menopause khususnya yang terkait dengan fungsi seksual bagi wanita menopause agar wanita menopause dapat memiliki fungsi sekusual yang baik.

\section{DAFTAR PUSTAKA}

Haryono, R., 2016. Siap Menghadapi Menstruasi \& Menopause. Yogyakarta: Gosyen Publishing

Lingga, L., 2011. Gampang \& Pasti Langsing. Jakarta: AgroMedia Pustaka

Melliana, A., 2006. Menjelajah Tubuh Perempuan dan Mitos Kecantikan. Yogyakarta: LKiS Yogyakarta

Pangkahila, W., 2014. Seks dan Kualitas Hidup. Jakarta: Kompas

Rosen, R., Brown, C., Heiman, J., 2000. Female Sexual Function Index (FSFI): A Multidimentional self-report instrument for the assesment of famale sexual function . 191-208

Smart, A., 2010. Bahagia di Usia Menopause. Jogjakarta: A+Plus Books 
Sugani, S., 2010. Cara Cerdas Untuk Sehat:

Rahasia Hidup Sehat Tanpa Dokter.

Jakarta: Trans Media Pustaka

Sunaryo., 2015. Asuhan Keperawatan

Gerontik. Yogyakarta: ANDI

Susanti, E., 2014. Hubungan Dukungan

Suami dengan Tingkat Kecemasan Istri

dalam Menghadapi Menopause. Jurnal

Biometrika dan Kependudukan, Vol. 3,

No. 2 Desember 2014: 114-119

Williams, L., \& Wilkins., 2011.

Fundamentals of Nursing; The Art and

Science of Nursing Care $\left(\begin{array}{ll}7 & \text { ed.). }\end{array}\right.$

Philadelphia: Wolters Kluwer Health

Windhu, S. C. 2009. Disfungsi Seksual;

Tinjauan Fisiologi dan Patologis

Terhadap Seksualitas. Yogyakarta:

ANDI

Wirawan, I., 2013. Segala Hal Tentang

Kesehatan yang Wajib Anda Ketahui.

Jakarta: Noura Books 